\title{
La estructuración de la danza azteca a causa del turismo entre sus grupos precursores en el Centro Histórico de la Ciudad de México
}

\author{
José Alejandro López Díaz*
}

Investigador independiente (México)

\section{Graciela Cruz Jiménez** Omar Ismael Ramírez Hernández**** Lilia Zizumbo Villarreal***** \\ Universidad Autonoma del Estado de México (México)}

\begin{abstract}
Resumen: Este artículo analiza la estructuración de la danza azteca a causa del turismo en el Centro Histórico de la Ciudad de México, mediante la Teoría de la Estructuración, apoyada por las aportaciones conceptuales de Bonfil Batalla. Las categorías de análisis fueron los elementos culturales propios y ajenos, resistencia, enajenación e innovación. La investigación fue cualitativa basada en la etnografía sociológica. Se comprobó que el turismo ha causado estructuración en la danza azteca, transformado sus elementos culturales, dividiendo a los danzantes en dos tendencias: chimaleros (mercantilizan y espectacularizan la danza para el turista) y culturales (grupos en resistencia ante los efectos del turismo). Se concluye, entre otros aspectos que, independientemente de su postura, ambos experimentan innovación, pues adaptarse les permite permanecer en el espacio turístico. Se reflexiona que la estructuración es un proceso natural de la sociedad, pero que el turismo genera cierta aceleración de las transformaciones en las prácticas sociales.
\end{abstract}

Palabras Clave: Estructuración; Turismo; Danza; Azteca; Enajenación; Resistencia; Espectacularización.

The structuring of Aztec dance for tourism consumption among its original group in the Historical Centre of Mexico City

Abstract: This paper analyses how traditional Aztec dance has been structured as a result of tourism in Mexico City's Historical Centre, based on the Theory of Structuration, as conceptualized formally by Bonfil Batalla. The categories of analysis were local and foreign cultural elements, resistance, alienation and innovation. The qualitative research was based on sociological ethnography. The results showed that tourism has caused structuring of traditional Aztec dance, transforming its cultural elements and dividing the dancers into two strands: the chimaleros (who commercialize and dramatize the dance for tourist consumption) and the traditional cultural groups (who resist the effects of tourism). Among other aspects, it is concluded that, regardless of their position, both have undergone adaptive innovation to remain inserted in tourism. It is reflected that trans-structuring is a natural process in society, but that tourism may generate a number of transformations in social practices.

Keywords: Structuration; Tourism; Aztec; Dance; Alienation; Resistance; Spectacularization.

\section{Introducción}

La danza es una manifestación cultural que por décadas ha sido incorporada como un atractivo turístico de México, generando con ello una interacción de prácticas sociales que provoca efectos en la

\footnotetext{
* Investigador independiente (México); E-mail: cold_fire1985@yahoo.com; http://orcid.org/0000-0003-4793-3177

** Universidad Autonoma del Estado de México (México); E-mail: gracicj@hotmail.com; http://orcid.org/0000-0003-0608-4682

*** Universidad Autonoma del Estado de México (México); E-mail: omar.ramirez.hdez@hotmail.com; https://orcid.org/0000-0002$-0874-5627$

***** Universidad Autonoma del Estado de México (México); E-mail: lzv04@hotmail.com
} 
sociedad receptora, pero también en la emisora. Según Fuller (2009: 20), el turismo puede ser entendido como una consecuencia de la globalización de la economía y de la cultura, porque permite a sus clientes acceder de manera directa, aunque episódica, a otras culturas y a otros lugares.

De esa forma, las sociedades insertan su cultura al mundo de la mercantilización y del espectáculo, por lo cual el turismo ha transformado incluso sus lugares geográficos como playas, bosques, selvas pueblos y ciudades en escenarios de consumo (Flores y Nava L., 2016: 9). En esta dinámica, el capitalismo no avanza eliminando las culturas tradicionales, sino apropiándose de ellas, reestructurándolas, reorganizando el significado y la función de sus objetivos, creencias y prácticas (Canclini en Flores y Nava, 2016: 9).

Para el caso de México, en algunas comunidades mayas donde se practica turismo étnico, Fernández y Estrada (2014) advierten que en realidad los turistas no consumen la cultura en su manifestación original; por ejemplo, en Ya'axnaj, dos organizaciones, una nacional, Conservación y Desarrollo A.C. y otra estadounidense, Advocating for a Better World, organizan espectáculos con el único fin de generar el consumo del patrimonio cultural de la población maya mediante una escenificación. Asimismo, estos autores afirman que el espectáculo pone en escena bienes y prácticas culturales que demandan los turistas, pero esconde, bajo la idea de revaloración cultural, la mercantilización de estos bienes y prácticas.

En este artículo se aborda la influencia del turismo en la estructuración de la danza azteca que han experimentado los grupos que la practican en el Centro Histórico de la Ciudad de México, sitio donde se erigió la gran ciudad mexica de Tenochtitlan y, que, por tanto, es un espacio ancestral sagrado para estos grupos. Es además un sitio de relevancia turística, pues según la Secretaría de Turismo, arriban anualmente a la Ciudad de México 11,451,339 turistas nacionales e internacionales (SECTUR, 2018).

En tal sentido, la interacción entre los grupos de danza azteca y los turistas es inevitable, por lo cual se ha convertido en un atractivo para los turistas que buscan tener un encuentro más cercano con la cultura originaria de la región centro del país, donde algunas agrupaciones la exhiben como un espectáculo o actividad con la cual lucran.

Con base en ello, se plantea que el turismo puede convertir las manifestaciones culturales en productos turísticos de consumo y por ende las transforma para volverlas mercantilizables, o en palabras de Fuller (2009: 94), el turismo propicia modificaciones culturales de manera acelerada porque las poblaciones receptoras las adaptan a las demandas del mercado y al deseo de los visitantes.

Cabe mencionar que la importancia del resguardo de dicha práctica social estriba en la valoración de que es objeto por aquellos grupos que la conservan y por la comunidad local en general, porque es parte de su patrimonio e identidad cultural; esto lo confirma de la Torre (2007), al afirmar que en la actualidad, tal manifestación "ha representado un bastión de la memoria y de la tradición indígena, entre las clases subalternas urbanas de México", por lo que se han conformado nuevos grupos urbanos en toda la Ciudad de México, cada uno con formas particulares de expresión. En este sentido, aunque a simple vista todos estos grupos de danza parecen iguales, generalmente se clasifican en dos:

- Calpullis de mexicanidad: Practican la danza azteca como un culto original de antecedente prehispánico.

- Mesas de concheros: Grupos que practican la danza azteca como un culto de origen prehispánico sincretizado con el culto católico.

Ambos grupos se encuentran inmersos en el contexto turístico y experimentan su influencia sobre sus prácticas sociales; por tanto, se les denominará de forma genérica como grupos de danza azteca. En este contexto, se expone la forma en que el turismo ha intervenido como un factor de su estructuración y transformación. Para atender tal propósito, con base en las propuestas de Anthony Giddens, fueron seleccionadas las categorías de análisis para analizar la estructuración de la danza azteca.

\section{Fundamentación teórico-conceptual}

En este artículo se analiza la interacción de una cultura dominante y una cultura subalterna como lo indica Bonfil (1991); la primera es aquella sociedad que impone sus elementos culturales sobre el grupo subalterno, el cual debe adaptarse a las condiciones que le son impuestas. Dicha adaptación tiene 
lugar mediante varios procesos, algunos de los cuales, según Bonfil (1991: 185-186), son la enajenación, la resistencia y la innovación.

En tal sentido, existen algunos casos de relaciones de dominación-sujeción entre la cultura dominante occidental, propiciados por el turismo, y las culturas subalternas de Anáhuac ${ }^{1}$ que habitan en los destinos turísticos que, generalmente, poseen un patrimonio cultural y/o natural explotable por dicho sector, propiciando la transformación de sus entornos y sus prácticas sociales.

Así sucede con los grupos que reproducen la danza azteca en el Centro Histórico de la Ciudad de México, donde la imposición del turismo como una importante actividad económica, genera en ella procesos de enajenación, resistencia e innovación que, a su vez, alteran sus elementos culturales materiales, simbólicos y organizativos, para adaptarla al espacio turístico.

Por tanto, la transformación de esta manifestación dancística puede ser explicada a partir de la teoría de la Estructuración de Anthony Giddens (1995), la cual sostiene que los sistemas sociales y sus formas específicas de organización se reproducen mediante las actividades de los individuos en sus vidas cotidianas, donde la estructura y la acción son elementos complementarios que en su conjunto conforman 'la dualidad de la estructura' (Thompson, 1988). Esto significa que por medio de las prácticas sociales se reproduce la estructura social y, viceversa; es decir, se produce una estructuración.

En este artículo se plantea que la estructura está conformada por los elementos culturales materiales, simbólicos y organizativos de la danza azteca, donde ya están implícitos las reglas y recursos, inherentes a la propuesta de Giddens (1995). La acción se visualiza como la práctica recursiva de esta manifestación cultural entre sus grupos precursores del Centro Histórico de la Ciudad de México. En tal sentido, la estructuración sucede por la recursividad de las prácticas sociales que reproducen las estructuras (elementos culturales) y son esas mismas estructuras las que ordenan y permiten la reproducción de las prácticas sociales; en dicha dinámica existen innovaciones que facilitan a las sociedades adaptarse a los cambios de su entorno, pero al interferir un factor ajeno como el turismo, se generan procesos acelerados de estructuración mediante la enajenación y la resistencia.

Por tanto, para observar las transformaciones que ha propiciado el turismo en los elementos culturales de la danza azteca practicada en el referido espacio, se recurrió a los grupos locales que la mantienen viva. A partir de ello, se observaron sus elementos culturales propios, que según Bonfil (1991: 173), son aquellos que la unidad social considera como su patrimonio cultural heredado de generaciones anteriores y los que produce, reproduce, mantiene y trasmite; del mismo modo, se observaron los elementos culturales ajenos, entendidos como aquellos que forman parte de la cultura que vive el grupo, pero que éste no ha producido ni reproducido, como es el turismo.

Se precisa que, dichos elementos se transforman y se conservan históricamente; en otras palabras, se estructuran al someterse a los procesos de:

- Resistencia: Cuando el grupo subalterno actúa en el sentido de preservar los contenidos concretos del ámbito de su cultura (Bonfil, 1991: 185).

- Enajenación: Mediante este proceso el grupo dominante aumenta su control cultural al obtener capacidad de decisión sobre elementos culturales propios del grupo subalterno (Bonfil: 1991: 186).

- Innovación. Mediante ésta, un grupo étnico crea nuevos elementos culturales propios (Bonfil, 1991: 185). Aunque, también puede modificar o sustituir los ya existentes, o en su caso, adherir elementos ajenos.

La resistencia genera procesos de conservación, resguardo y rescate de los elementos culturales de la danza azteca, mientras que la enajenación propicia su espectacularización y mercantilización. En ambos casos hay innovaciones que derivan en procesos de invención, modificación, adición y sustitución.

Dichas categorías y subcategorías se agrupan, tal como se muestra en la imagen 1.

Asimismo, la estructuración provocada por el turismo es causada en gran parte por la enajenación, ya que, según Bonfil (1991: 175), la folclorización (sinónimo de espectacularización) de fiestas y ceremonias para su aprovechamiento turístico, propicia que, elementos de organización, materiales y simbólicos propios, queden bajo decisiones ajenas y, en consecuencia, forman parte del ámbito de la cultura enajenada. Para Dorson (1963), la escenificación modernizada y espectacularizada de las tradiciones genuinas de una cultura se puede resumir en la palabra "fakelore", la cual, implica también la mercantilización de dichas tradiciones, señalamiento que coincide con las afirmaciones de Bonfil (1991), y que es aplicable al ámbito del turismo. 
Imagen 1: Categorías y subcategorías en la estructuración de la danza azteca

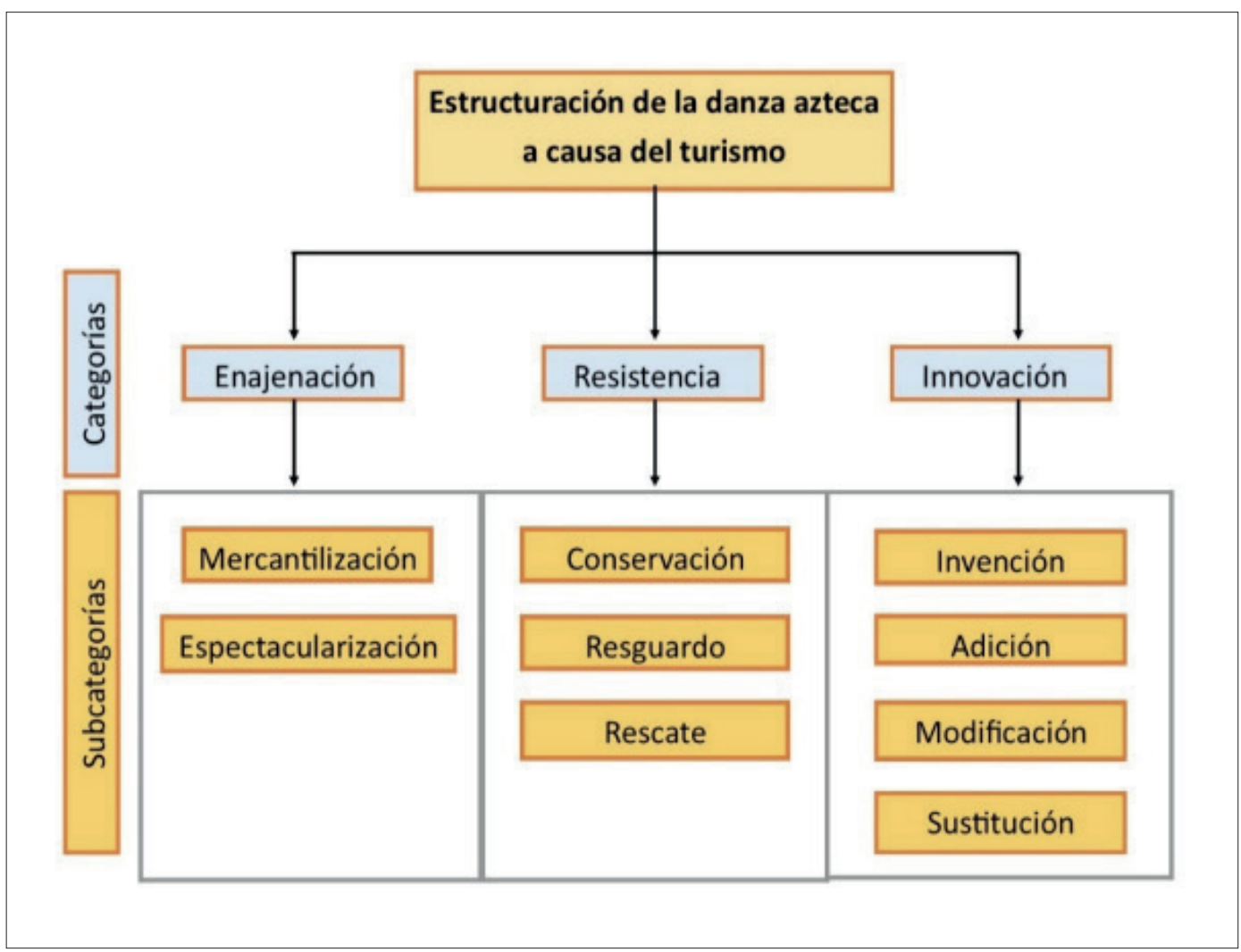

Fuente: Elaboración propia.

\section{Propuesta metodológica}

La investigación en que se basa este artículo fue cualitativa, pues para el caso de manifestaciones culturales como la danza azteca y su relación con el turismo, este tipo de acercamiento metodológico es el más pertinente para abordar la dinámica social y su estructuración, ya que el método cualitativo propone modelos de investigación como el etnográfico, que en palabras de Goetz (1988) refiere a "uno de los modelos generales de investigación utilizados por científicos sociales para el estudio del comportamiento humano". El tiempo para realizar el trabajo de campo fue limitado, por lo cual se recurrió a la etnografía sociológica (o enfocada), que permitió obtener la información necesaria para apoyar el propósito del estudio. El cuadro 1 muestra las diferencias entre la etnografía tradicional y la etnografía sociológica, de acuerdo con Montes de Oca (2015).

Para identificar las principales transformaciones en los elementos culturales de la danza azteca, que obedecen a una enajenación para el agrado de los turistas, la investigación siguió la siguiente secuencia metodológica: En primer término, se efectuó la revisión bibliográfica y hemerográfica de libros, revistas, artículos, bases de datos y periódicos, para tener un contexto más amplio sobre los elementos culturales materiales, simbólicos y de organización que conforman a las agrupaciones de este tipo de danza y, formular el fundamento teórico-epistemológico.

Posteriormente fueron diseñados y aplicados los instrumentos de investigación; se realizaron acercamientos exploratorios y entrevistas a personajes clave pertenecientes a los calpullis grupos de danza azteca, para procurar un acercamiento a la estructura de ésta, lo que implicó el conocimiento de sus elementos culturales propios, que fueron clasificados en materiales, simbólicos y organizativos; a su vez, tales elementos constituyen las "reglas y recursos" de la estructura. 
Cuadro 1: Etnografía tradicional y Etnografía sociológica (enfocada)

\begin{tabular}{|c|c|}
\hline Etnografía tradicional & Etnografía enfocada \\
\hline Visitas largas a campo & Visitas cortas a campo \\
\hline $\begin{array}{l}\text { Intensidad temporal de la información } \\
\text { construida }\end{array}$ & Intensidad de la información construida \\
\hline Énfasis en la escritura (notas) & $\begin{array}{l}\text { Combinación de escritura y grabación } \\
\text { (notas y transcripción de audio y video) }\end{array}$ \\
\hline $\begin{array}{l}\text { Mirada holística en todos los aspectos } \\
\text { del campo }\end{array}$ & $\begin{array}{l}\text { Mirada enfocada a ciertos aspectos del } \\
\text { campo }\end{array}$ \\
\hline $\begin{array}{l}\text { Sociedades ajenas (estudio de lo extraño: } \\
\text { strangeness) }\end{array}$ & $\begin{array}{l}\text { Sociedad propia (estudio del alter ego; } \\
\text { alterity) }\end{array}$ \\
\hline Aprender el idioma nativo & $\begin{array}{l}\text { Familiarizarse con el lenguaje particular } \\
\text { (sociolectos: tecnicismos, argot, no verbal) }\end{array}$ \\
\hline
\end{tabular}

Fuente: Montes de Oca (20015)

Las categorías de análisis contenidas en las entrevistas fueron las siguientes; algunas de ellas fueron observadas en paralelo:

- La interacción entre instituciones interculturales: consiste en observar la interacción entre la cultura local subalterna y la cultura dominante en el Centro Histórico de la Ciudad de México, dada mediante la recursividad de la institución de la danza azteca y la institución del turismo.

- Elementos culturales propios: Elementos materiales, simbólicos y organizativos propios de la danza azteca.

- Elementos culturales materiales: Atuendos, instrumentos musicales e insumos utilizados en la ejecución de la danza azteca.

- Elementos culturales simbólicos: Conocimientos, códigos de comunicación, creencias y valores integrados en la danza azteca, que motivan y dan sentido a su continuidad.

- Elementos organizativos: Formas de relación social sistematizadas que posibilitan la participación de los miembros del grupo para reproducir la danza azteca. En esta categoría se integran los reglamentos y protocolos que siguen los grupos estudiados.

Paralelamente tuvo lugar la observación participante, tomando parte como observador y danzante azteca en diversos eventos, lo que permitió registrar la experiencia vivencial de la práctica social estudiada.

Como parte del trabajo de campo se efectuaron tres visitas exploratorias durante 2019 y una estancia durante el mes de enero del 2020, en ambos casos en los sitios correspondientes a la zona de estudio con mayor concentración de grupos de danza, como la plaza Manuel Tolsá, el monumento a la Mexicanidad, la Plaza Manuel Gamio y las inmediaciones de la Catedral Metropolitana.

Finalmente, los datos obtenidos en campo fueron contrastados con la información teórica, lo cual permitió tener un panorama más amplio sobre la estructuración de la danza azteca por causa del turismo, tal como se expone en el siguiente apartado.

\section{Resultados}

\subsection{La estructuración en los grupos precursores de la danza azteca}

Los grupos precursores de la danza azteca del Centro Histórico de la Ciudad de México, quienes representan la cultura subalterna local, mantienen una estrecha relación con la práctica social del turismo por medio de dicha manifestación cultural; se reitera que, tal hecho ha provocado la enajenación de algunos de ellos, mientras que otros se manifiestan en resistencia; en consecuencia, según sus testi- 
monios, se han dividido entre grupos chimaleros y culturales. Ambos experimentan de forma diferente su estructuración. Una de las categorías de análisis que se vincula a este proceso, es la enajenación.

\subsection{Enajenación de los grupos chimaleros en el contexto turístico}

Aquellos que por sus características tienden hacia la enajenación son los grupos denominados entre los danzantes como chimaleros, que han incorporado variadas adaptaciones, porque el turismo ha generado en ellos un interés lucrativo, mercantilizando la danza azteca mediante una escenificación espectacularizada en espacios públicos. Su intención es que sea apreciada principalmente por los turistas y los locales, quienes de manera voluntaria les hacen aportaciones económicas, práctica que ellos mismos han denominado chimaleo.

De esta forma, se han enajenado al incorporar su práctica social a las dinámicas del turismo (factor cultural ajeno). En tal sentido, se visualiza la enajenación como la causa del chimaleo que espectaculariza y mercantiliza la danza objeto de análisis. A su vez, tal situación genera procesos de resistencia e innovación que han permitido a estos grupos adaptarse al contexto turístico, como se explica en el siguiente apartado.

\subsection{La enajenación como causa de resistencia}

Mantener la danza azteca como el activo mercantil en el espacio turístico requiere de la conservación, resguardo y rescate de algunos de sus elementos culturales; así lo han hecho los chimaleros para montarla en escena y ser notados por los turistas. Por ejemplo, en lo organizativo la continúan ejecutando en círculo, a cuyo centro van pasando uno a uno los integrantes, con una coreografía apegada al protocolo original: cada uno hace primero la firma (reverencia a los cuatro elementos) de permiso, después danza mientras los demás siguen sus pasos y, para concluir su participación hace otra firma de agradecimiento; entonces sigue el turno a otro danzante chimalero, quien realiza el mismo procedimiento. También se conserva la figura de un huehuetero, quien se encarga de tocar el huehuetl (tambor tradicional mexica).

Dichas formas de organización implican además la conservación de ciertos elementos simbólicos; por ejemplo, el tlalmanalli (ofrenda central) contiene los cuatro elementos sostenedores de la vida en la cosmovisión mexica, los cuales, se colocan sobre cuatro paliacates de colores direccionados cada uno con el rumbo que le corresponde. De igual forma, el huehuetl simboliza el corazón del círculo de danza y la conexión con Coatlicue (la madre tierra).

En cuanto a la forma de ejecutar la danza, el círculo simboliza el cosmos, lo infinito, la igualdad y la unión, mientras que, la firma es una forma de reverenciar a los cuatro elementos. Otro elemento simbólico que conservan es, la ejecución de una apertura de danza, pidiendo permiso a los cuatro rumbos del universo, sahumándose antes de entrar al círculo. Esa acción es congruente con lo referido por los entrevistados, quienes aseguran que, para ellos, la danza azteca continúa siendo una práctica ritual de carácter sagrado, independientemente del ingreso económico que obtienen.

Por otra parte, en lo referente a los elementos materiales, conservan el uso de coyoleras (tobilleras con cascabeles), ixcualmecatl (cinta que se coloca en la cabeza), fajas, maxtles (mal llamado taparrabo), pectorales, adornos de pedrería, arte plumario y huaraches, además de manta y pieles para confeccionar sus prendas; en lo que respecta a los insumos y accesorios, preservan el uso de flores y frutas para hacer un tlalmanalli (ofrenda); incluso continúan empleando canastas elaboradas con fibras vegetales, así como vasijas de barro para el agua (Tláloc) y popochcomitls y tlemaitls (especies de sahumerios) donde queman copal. Algunos instrumentos musicales que siguen utilizando son el huehuetl (tambor), ocarinas de barro, flautas de carrizo, ayacaxtles (sonajas) y atecocolli (trompeta de caracol marino). Asimismo, han rescatado algunos rasgos de la vestimenta de los antiguos guerreros águila y jaguar, para generar mayor vistosidad y atracción al ponerlos en escena.

Por otra parte, destaca la recuperación de algunos elementos culturales originales promovida por los grupos culturales (no lucran con la danza), quienes portan atuendos sobrios y confeccionados con manta, a fin de inhibir la espectacularización que ha provocado la enajenación por el turismo. Esto se aprecia principalmente en la reducción del uso plumas.

Paralelamente, la enajenación por el turismo ha provocado en los grupos chimaleros un proceso de innovación que les permite mercantilizar y espectacularizar la danza azteca, lo cual atenta contra el resguardo o protección de sus elementos culturales propios y, por ende, contra su originalidad y finalidad primigenia.

\subsection{La enajenación como causa de innovación}

La innovación provocada por el turismo en esta manifestación cultural, genera procesos acelerados de invención, modificación, adición y sustitución en sus elementos culturales. En tal sentido, una modificación 
importante en la organización de los chimaleros es que se congregan en agrupaciones menos numerosas, cada una entre cinco a 10 individuos; de esta forma, el dinero que obtienen se reparte entre menos personas.

Paralelamente, han modificado la ocupación del espacio; al danzar ya no forman un gran círculo entre todos los grupos, sino que se distribuyen del siguiente modo: en el costado poniente de la catedral se ubica la minoría de grupos (dos), mientras que en la Plaza Manuel Gamio se concentra la mayoría (entre cinco y siete cada día), colocándose uno al lado de otro de forma independiente, para no danzar al mismo tiempo, pues de hacerlo se mezclaría el sonido de sus huehuetls. Por ello, los grupos participan por turnos y descansan 20 minutos entre cada uno; mientras tanto, realizan otras actividades lucrativas, como la venta de artesanía, pedrería, libros sobre la cultura mexica, limpias energéticas y ajustes de cuerpo ${ }^{2}$.

Las danzas de los grupos asentados en la Plaza Manuel Gamio son presenciadas por mayor número de turistas, debido a su ubicación entre la Catedral Metropolitana, el Museo del Templo Mayor, el Zócalo y las salidas del sistema de transporte colectivo (metro).

Otra modificación que han sufrido los elementos organizativos entre los grupos chimaleros, es que no realizan auténticas ceremonias de danza; a lo largo del día, durante los turnos que les corresponde, cada grupo presenta escenificaciones cortas (cuatro danzas en 15 minutos aproximadamente), con la intención de no entretener demasiado a los turistas y transeúntes.

Además de las fechas especiales del calendario mexica y de las festividades concheras, han ampliado su presencia a los días de mayor afluencia turística; por ello, chimalean los jueves, viernes, sábados y domingos en la Plaza Manuel Gamio y, al costado poniente de la Catedral Metropolitana, entre las 11:00 am y 6:00 pm.

Otra práctica que han incorporado los grupos chimaleros con la cual amplían el círculo de danza, es el palomazo, que consiste en integrar a miembros de otros grupos, a quienes no les comparten el dinero recolectado, pero en un acto de reciprocidad los apoyan cuando a ellos les corresponde danzar.

Adicionalmente, estos grupos han invitado a sanadores o chamanes dedicados a realizar limpias o ajustes de cuerpo; algunos no danzan, por lo cual no portan un atuendo para tal fin, pero usan ropa de manta blanca y el ixcualmecatl como protección contra las malas vibras. Al terminar la jornada laboral, tanto los sanadores como los danzantes se reparten equitativamente el dinero obtenido.

Del mismo modo, se han modificado los cargos: no hay topillis o segundas palabras (encargados del orden del grupo); tampoco tercera palabra, ni palabras de elementos o de huehuetl. Solamente existe una figura de autoridad como primer palabra y, en ocasiones, una segunda persona al mando, por lo cual la danza se ejecuta sin necesidad de una organización compleja, pues simplemente forman el círculo y ejecutan cuatro o cinco danzas en forma continua, hasta que otro grupo toma su turno. Asimismo, se ha incorporado un personaje cuya función es salir del círculo para solicitar cooperación económica a los espectadores.

Aunado a ello, los grupos chimaleros han transformado sus movimientos, volviéndolos exagerados, acelerados, bruscos y parafernálicos, para que luzcan más impactantes. Alotl Conde, antropólogo y líder del grupo cultural Ixnextli Xipetotec, quien durante mucho tiempo se dedicó a chimalear, explica:

tiene que ver con exposición de parafernalia [...], obvio que la danza tradicional es diferente [...], pero en una exposición dancística [...] las coreografías se deben ajustar para que la gente vea la espectacularidad y la fortaleza de la danza (Alotl Conde, comunicación personal, 31 enero 2020).

Otro hecho importante vinculado a la innovación de sus elementos organizativos, es el acoso de las instituciones del gobierno local que continuamente, por medio de los cuerpos de seguridad pública, intentan retirarlos del sitio turístico donde se presentan, argumentando que tienen órdenes de reordenamiento de espacios públicos (documento que no presentan). Este tipo de situaciones han orillado a los grupos chimaleros a cumplir las exigencias del Estado, por lo cual se han constituido como asociaciones civiles de difusión cultural; esto les permite diferenciarse de los vendedores ambulantes que continuamente son removidos por las fuerzas policiacas.

Otro dato importante es que carecen de permisos formales de uso de suelo; en su defensa, solo presentan algunas cartas de consentimiento emitidas por algún funcionario público con quien tienen contacto.

Por otra parte, también se hace evidente la innovación en los elementos materiales, cuando los chimaleros despliegan gran espectacularidad en sus atuendos, en particular la adición exagerada de plumas de distintas aves, como guacamaya, faisán, perico, águila, zopilote, búho y lechuza, entre otras, que portan principalmente en sus grandes copillis (tocados para la cabeza). También se observa la incorporación de pieles y osamentas de animales, además de un ligero uso de pintura facial que da una apariencia estética.

Otro dato sobresaliente observado y manifestado en las entrevistas, es que algunas mujeres han sustituido las faldas, huipiles y quexquemetls por prendas masculinas, como el maxtle y el pectoral, esto 
con motivos de vistosidad y algunas veces por falta de conocimiento. Por ello existe una gran variedad de estilos en que la manta ha sido remplazada por telas satinadas y coloridas en atuendos modificados con aberturas laterales en las faldas y adornos con motivos mexicas.

El vestuario de los hombres es similar al de algunas mujeres, pero a ellos sí les corresponde usar el maxtle y pectoral. También resalta la adición de máscaras de esqueleto o pintura facial, así como una especie de mameluco que cubre el cuerpo desde el cuello hasta los tobillos, confeccionado con tela sintética y elástica que les permite danzar cómodamente y los cubre del sol; éste sustituye a los mamelucos que usaban los antiguos guerreros, confeccionados con fibras naturales o pieles. Asimismo, se observó el uso de colas de caballo en la parte trasera del copilli, con una función meramente estética, lo cual es un elemento ajeno.

De igual forma, resalta el uso de trajes de luces, un estilo de prendas inspiradas en los ballets folclóricos, adornadas con material plástico brilloso en tonalidades oro o plata; según los danzantes, es utilizado para sustituir los metales preciosos que usaban los antiguos mexicas en sus atuendos.

Por otra parte, algunos danzantes contemporáneos usan yelmos, asemejando cabezas de águila, accesorio rescatado de los antiguos códices, aunque los materiales tradicionales fueron sustituidos por plásticos y tela, a los cuales les añaden plumaje para hacerlos más vistosos. Este tipo de atuendos sugiere que mediante la enajenación también pueden generarse procesos de resistencia, pues los grupos buscan rescatar las formas de los atuendos antiguos, pero la finalidad es espectacularizar la danza para atraer a turistas y espectadores locales, para obtener más ingresos.

En lo que respecta a los instrumentos musicales originales, la única innovación es la sustitución de los troncos de madera por tambos metálicos en la fabricación de los huehuetls; a diferencia de las otras, esta no fue provocada por el turismo, sino para reducir su costo, pese a la resistencia a modificar los instrumentos musicales.

Respecto a los elementos simbólicos, se comprobó que la mayoría de los grupos chimaleros se han enajenado por la mercantilización de la danza azteca para el turismo, volviéndola un espectáculo, dejando de lado su finalidad original como ritual sagrado y el objetivo de difundir la cultura; incluso evitaban las entrevistas argumentando que estaban trabajando o pretendían cobrar por ellas para compensar el dinero que dejarían de percibir mientras respondían las preguntas. No obstante, una minoría de grupos aportaron tiempo y dedicación para apoyar la investigación sin un interés económico e incluso permitieron la Observación Participante, principalmente los calpullis Ce Mazatl, y Mazacoatl a cargo de Temiki (Domitila) y de Itztli (José Luis), respectivamente.

Es importante señalar que el turismo no ha tenido la misma influencia en todos los grupos, pues en general, los chimaleros se caracterizan por sus danzas espectacularizadas con un afán de lucro, contrario a los grupos culturales. A pesar de que estos últimos también han experimentado su estructuración por actuar en el Centro Histórico de la Ciudad de México, se observa una nula tendencia a la enajenación por el turismo; más bien experimentan un proceso de resistencia que ocasiona una constante innovación.

Para contrastar las características de la estructuración por turismo descritas sobre los grupos chimaleros y la diferencia con los grupos culturales, en el siguiente apartado se detalla cómo los segundos se relacionan con el turismo, la forma en que ejecutan esta danza, sus propósitos y, los elementos culturales observados en ellos.

\subsection{La resistencia de los grupos culturales ante el turismo}

Este tipo de grupos no están inmersos en la dinámica de la enajenación por el turismo, pues no chimalean, ya que no lucran con la danza azteca, ni tampoco la escenifican para presentarla ante el turista. En cambio, se manifiestan como una forma de resistencia ante la estructuración provocada por prácticas sociales modernas como el turismo. Ellos procuran la conservación, resguardo y rescate de la cultura ancestral de México-Tenochtitlan, mediante la reproducción de esta práctica social; en consecuencia, presentan resistencia ante los procesos de mercantilización y espectacularización, resguardando los elementos culturales propios de esta manifestación cultural.

\subsection{La resistencia, proceso que inhibe la enajenación}

El número de integrantes en los grupos culturales es variable, pues al no chimalear no limitan a los nuevos participantes; por tanto, algunos grupos varían entre 30 hasta 150 danzantes aproximadamente. La mayoría de ellos se reúne para ensayar los sábados en la Plaza Manuel Tolsá, la calle Xicoténcatl (junto a la antigua Sede del Senado de la República), en el costado poniente de la Catedral Metropolitana, en la Plaza Manuel Gamio y en el Monumento a la Mexicanidad (o a la Fundación). Argumentan que danzan en el Centro Histórico por ser un lugar sagrado para ellos, pues debajo de la actual ciudad se 
encuentra la antigua ciudad de sus ancestros, México-Tenochtitlan. Por tanto, rechazan que el motivo tenga que ver con la significativa circulación de turistas en la zona.

Otra característica de estos grupos es que la mayoría son mexicanistas; no obstante, algunos son mixtos porque ejecutan simultáneamente las dos vertientes de la danza (mexicanista y conchera). Por tal razón, además de ensayar en el lugar, también llevan a cabo ceremonias durante los días festivos del calendario mexica o, en algunas ocasiones, del santoral católico; de igual forma, realizan otras actividades de difusión cultural, como clases de canto y de danza para nuevos integrantes.

Asimismo, estos grupos realizan sus ensayos sabatinos ininterrumpidamente durante dos o más horas continuas, en cambio, realizan las ceremonias cualquier día del año y pueden durar hasta siete horas. Durante este tiempo, son vistos por turistas y espectadores locales, quienes toman fotografías y videos, se acercan a preguntar e incluso a danzar. Además, resguardan el carácter sagrado de la danza, ya que respetan y hacen que se respete el círculo de danza, por lo que no permiten que la gente ajena y los turistas se atraviesen por en medio, ni ingresen al círculo a tomar fotografías o videos; pero si desean integrarse, los hacen entrar por la puerta, donde los sahúman y les asignan un lugar en el círculo donde pueden danzar siempre y cuando mantengan una actitud respetuosa.

Contrario a los chimaleros, estos grupos no están limitados a usar un solo huehuetl durante sus ceremonias y ensayos, por lo cual conservan la práctica de utilizar varios tambores al centro del círculo de danza.

Respecto a la organización jerárquica de la danza, se constató que mantienen la forma tradicional mexicanista y/o conchera. Por tanto, salvaguardan el orden de los pasos para realizar una ceremonia, pues previo al inicio, la persona denominada el/la primer palabra (coordinador de la danza) determina quiénes tomarán los demás cargos y les entrega la palabra (la responsabilidad que les corresponde).

Posteriormente forman el círculo de danza y solicitan permiso a los cuatro rumbos para comenzar; a ello le sigue una serie de danzas que van siendo otorgadas a algunos danzantes por la o las terceras palabras; el cierre incluye agradecer a los rumbos y finalmente se reúnen en círculo para promover la asistencia a otras danzas. Este procedimiento comprueba que los grupos culturales han rescatado, conservado y resguardado las formas tradicionales de esta manifestación.

Por otra parte, uno de los aspectos en la organización de los grupos culturales que se ha estructurado, es que, al igual que los grupos chimaleros, varios se han tenido que constituir como Asociaciones Civiles porque también son acosados constantemente por los cuerpos policiacos y han padecido el mismo hostigamiento de todos los grupos de danza azteca del Centro Histórico de la Ciudad de México.

En lo referente a los elementos materiales, los integrantes de los grupos culturales portan atuendos más sobrios que los chimaleros y procuran rescatar las confecciones originales; en tal sentido, aunque no buscan agradar al turista o al espectador, se pudieron observar algunas innovaciones; por ejemplo, algunos hombres en vez de usar maxtle y pectoral, portan pantalón de manta, en ocasiones con la parte superior descubierta o con una camisa o guayabera, incluso han incorporado el uso de sombreros, pero conservando la faja, el ixcualmecatl, las coyoleras y los huaraches. Por su parte, las mujeres usan falda y blusa de manta; en ocasiones añaden quexquemetls que pueden ser de manufactura indígena o imitaciones hechas por los mismos danzantes con diversos materiales.

Este tipo de atuendos no necesariamente corresponden al estilo de la época precuauhtémica ${ }^{3}$, más bien, son una innovación en que los danzantes sustituyen los atuendos mexicas originales por la vestimenta actual de las comunidades nahuas tradicionales.

También se observa dentro de estos grupos, una corriente de grupos mexicanistas más ortodoxa, quienes intentan rescatar la confección de los atuendos de la época precuauhtémica; por ello existe una tendencia a usar maxtles, pectorales, faldas, quexquemetls y huipiles, pero no todos los atuendos de este estilo son elaborados con manta o algodón como se hacía antiguamente, ya que algunos sustituyeron esos materiales por otros más económicos y fáciles de manejar, como el lino.

Asimismo, aunque entre los grupos culturales sea más evidente la resistencia, se constató que ciertos miembros usan trajes de luces, copillis con plumas; incluso, al igual que en los grupos chimaleros, algunas mujeres utilizan prendas masculinas, aunque es una tendencia en desuso y menos influyente entre los culturales.

También se evidenció que el uso de plumas es mucho menor al de los chimaleros, pues la mayoría de los culturales no las utilizan o solamente portan una rodela pequeña prendida al cabello con plumas de aves originarias, principalmente de águila, zopilote, búho, lechuza, guajolote y cuervo.

Respecto a los instrumentos musicales, al igual que en los grupos chimaleros, se evidencia mayor resistencia a modificarlos, por lo cual se han conservado y resguardado los instrumentos originales, aunque también se constató que en muy pocas ocasiones han sustituido la madera por el metal en la fabricación de huehuetls.

En lo que se refiere a los elementos simbólicos, se constató que los grupos culturales han resguardado los elementos culturales propios de la danza azteca al mantenerse apartados de la enajenación y, por 
ende, de los procesos de espectacularización y mercantilización. Ello quedó demostrado al comprobar que no practican el chimaleo, pues como ya se refirió, se presentan en un espacio turístico no motivados por el turismo en sí, sino porque lo consideran un lugar sagrado por estar situado sobre la antigua ciudad de México-Tenochtitlan.

En tal sentido, los culturales son grupos de resistencia que pretenden conservar, resguardar y rescatar los elementos culturales de esta modalidad cultural, sobreponiendo el valor simbólico sobre el mercantil.

Entre las prácticas que conservan, resguardan y rescatan, figuran el habla y la enseñanza de la lengua náhuatl; así como el respeto y veneración a las Energías sagradas (los danzantes argumentan que no son dioses) de la cosmovisión nahua, lo cual manifiestan al sahumar a cada uno de los danzantes previo a su integración al círculo; en pedir permiso a los cuatro vientos en náhuatl y en español antes de iniciar cualquier ceremonia o ensayo de danza.

También continúan presentando en sus tlalmanallis (ofrendas al centro del círculo) los cuatro elementos sostenedores de la vida: el agua en las vasijas Tláloc; la tierra en canastos llenos de fruta y flores; el viento con el uso del atecocolli (trompeta de caracol marino) y, el fuego en los popochcomitl y tlemaitl (sahumerios). Asimismo, portan adornos de flores alusivos a su cosmovisión.

Esta serie de elementos simbólicos, impregnan de un sentido sagrado a los elementos materiales y organizativos, por lo que el simbolismo y la cosmovisión mexica (y en menos casos la católica), marcan realmente las pautas determinantes de cómo, dónde y cuándo se debe ejecutar la danza azteca. En consecuencia, la mayoría de ceremonias en el Centro Histórico de la Ciudad de México correspondan a las fechas célebres del calendario mexica: veintenas, trecenas, equinoccios, solsticios, aniversario de la fundación de Tenochtitlan, aniversario luctuoso de Cuauhtémoc, aniversarios de calpullis, etcétera. No obstante, los minoritarios grupos mixtos (mexicas-concheros) también danzan los días alusivos a los santos patronos de sus barrios y colonias, presentándose en capillas, iglesias y en la Catedral Metropolitana.

A diferencia de los chimaleros, los grupos culturales no realizan una escenificación espectacularizada para ser apreciada por el turista; lo hacen con la intención de ensayar y celebrar sus ceremonias relevantes, lo cual es congruente con lo referido por los entrevistados de esta vertiente, para quienes la danza azteca es una práctica ritual de carácter sagrado, de ahí que desaprueban el chimaleo, por considerarlo una práctica en contra de sus principios.

Con lo planteado en este apartado se demuestra que los elementos materiales, simbólicos y organizativos de la danza azteca practicada por los grupos culturales se han visto poco influenciados por la relación con el turismo; más bien, su estructuración responde a un proceso de resistencia para adaptarse a los cambios contextuales de la Ciudad de México y a la tendencia de rescatar los elementos originales.

\section{Conclusiones}

Se observa que la interacción entre los grupos de danza azteca y el turismo es estrecha, pues como refiere de la Rosa (2003: 156), la "cultura y turismo no son dos esferas separadas, sino realidades que convergen en la vida cotidiana de numerosos actores. En primer lugar, en el quehacer rutinario de los turistas que tienen la ilusión de conocer y disfrutar de culturas diferentes a la propia. En un segundo frente, en la vida diaria de los habitantes en las comunidades receptoras que, en diferentes contextos, y de distintas formas, son conscientes de que su diferencia cultural es un atractivo turístico, y el turismo es una fuente de ingresos".

Esto se evidenció con la investigación empírica, pues se comprobó que el turismo, como institución de la cultura dominante, puede influir en la estructuración de las prácticas sociales de la cultura subalterna local, tal como sucede con la danza azteca en la zona de estudio, generando con ello procesos simultáneos de enajenación, resistencia e innovación entre los grupos que la ejecutan.

En tal sentido, se observó que los grupos locales que se integran a las dinámicas del turismo (chimaleros) mediante la enajenación, son los que han experimentado mayor transformación en sus prácticas sociales, ya que éstas, a pesar de conservar y rescatar sus elementos culturales propios para exponerlos ante el turismo, también se someten a procesos de innovación mediante los cuales se modifican o sustituyen dichos elementos, se inventan nuevos y se incorporan elementos ajenos. Por su parte, los grupos que se mantienen en resistencia (culturales) ante la enajenación por el turismo, no experimentan procesos de espectacularización y mercantilización en sus prácticas sociales, pero sí innovaciones que les han permitido adaptarse a su contexto actual.

Estas dos formas de estructuración de las prácticas sociales de una comunidad local que suceden en un contexto turístico, como es el Centro Histórico de la Ciudad de México, se observaron en los grupos de danza azteca (chimaleros y culturales). Aunque los primeros, experimentan un proceso de enajenación por el turismo y, los segundos se manifiestan como una resistencia ante los efectos de dicha actividad. No obstante, 
se constató que, independientemente de su postura, ambos experimentan un proceso de innovación constante, pues el hecho de adaptarse les ha permitido desarrollarse y permanecer en el espacio turístico actual.

Asimismo, se confirmó que los elementos materiales de la danza han sido objeto de diversas alteraciones, porque estos elementos son los más visibles para el turista, de ahí que se espectacularizan mediante la enajenación para hacerse mercantilizables, lo cual dio lugar a la práctica del chimaleo. En tal sentido, la enajenación puede llegar a trastocar los elementos simbólicos al provocar que se superponga el valor mercantil, lo cual atenta contra el carácter sacro de algunas prácticas sociales o instituciones de la cultura local, como la aquí analizada.

Asimismo, se comprueba que existen ciertas posturas intermedias por parte de algunos chimaleros que, si bien incurren en la mercantilización de esta manifestación cultural, procuran no espectacularizarla para presentarla en su forma original en la medida de lo posible, conservando y rescatando algunos de sus elementos culturales propios. Sin embargo, dicha actitud no escapa al proceso de enajenación; más bien, sus prácticas de rescate y conservación responden a un interés mercantil, más que a un carácter simbólico.

\section{Discusión}

Se entiende que la estructuración es un proceso natural de la sociedad que no está sujeto a la interacción intercultural, pero que, cuando el turismo se inserta en el territorio y en la cotidianidad de una cultura local a la que es ajeno, provoca ciertos efectos y actitudes diversas entre los locales, generando con ello algunas transformaciones en las prácticas sociales a causa de la enajenación.

De este modo, los postulados de la Teoría de la Estructuración de Giddens (1995) fueron pertinentes para abordar la realidad, aunque no toma en cuenta las relaciones interculturales de dominación-sujeción que pueden suscitarse en los contextos turísticos, como sucede en el Anáhuac4, por lo que fue necesario incorporar elementos conceptuales de la Teoría del Control Cultural de Bonfil (1991).

Esta complementariedad permitió comprender la estructura como el conjunto de elementos culturales materiales, simbólicos y organizativos que conforman la práctica social, y los procesos de enajenación, resistencia e innovación como parte de la estructuración a causa del turismo. En tal sentido, se espera que la investigación de que se deriva este artículo sirva de base para futuros análisis sobre la estructuración en contextos sociales donde exista una relación de subalternancia de las comunidades locales causada por el turismo. Asimismo, la investigación contribuye a cubrir un vacío de conocimiento sobre una problemática relacionada al turismo que está afectando a los grupos de danza azteca, que no se había abordado desde el ámbito académico.

Por otra parte, es necesario precisar que, aunque el turismo ha sido un factor importante que ha acelerado la estructuración de las prácticas sociales de la cultura local como la danza azteca, no es el único elemento que ha intervenido, pues la observación participante permitió visualizar otras problemáticas que enfrentan los grupos de danza azteca, como: la intolerancia de algunos grupos religiosos (de corte cristiano) hacia las espiritualidades anahuacas; la falta de apoyo de instituciones del Estado mexicano; el malinchismo manifestado por algunos habitantes locales y turistas nacionales, además de la intimidación policiaca.

Esta investigación abre otras posibilidades de estudio, entre ellas los procesos de apropiación que el turismo ejerce sobre los grupos de danza azteca, o en contraparte, cómo dichos grupos se han apropiado del concepto de turismo para reinterpretarlo.

Cabe mencionar que no existe una palabra que resuma en un solo término el fenómeno de "la estructuración causada por el turismo", lo cual complicaba su mención y llegó a generar confusiones de corte semántico, por ello se puede proponer la acuñación de un nuevo término que bien podría denominarse como "estructuristificación", sin embargo, al proponer dicho término es necesario realizar una fundamentación teórica y empírica más profunda que bien podría realizarse en un trabajo posterior.

\section{Bibliografía}

Bonfil, Guillermo 1991. La Teoría del Control Cultural en el estudio de procesos étnicos. Revista Estudios Sobre las Culturas Contemporáneas, Vol. IV, No. 12, Universidad de Colima, México.

De la Rosa, Beatriz 2003. Nuevos turistas en busca de un nuevo producto: El patrimonio cultural, Revista Pasos, Vol. 1, No. 2, Universidad de la Laguna, España.

De la Torre, Renée 2007. Alcances translocales de cultos ancestrales: El caso de las danzas rituales aztecas, Editorial Escuela Nacional de Antropología e Historia - Centro de Investigaciones y Estudios Superiores en Antropología Social Occidente, México. 
Dorson, Richard M. 1963. Current folklore theories. Revista Current Antropology, vol. 4, núm. 1. University of Chicago, Chicago, Estados Unidos. Consultado en https://www.jstor.org/stable/2739820 el 31 de agosto de 2020.

Fernández Repetto y Estrada Burgos 2014. Esencialización y espectacularización de lo maya: Turismo voluntario y étnico en una comunidad yucateca, Revista Península Vol. 9, Universidad Autónoma de Yucatán, México.

Flores Mercado G., Nava L. Fernando 2016. Identidades en venta: Músicas tradicionales y turismo en México. Editorial Universidad Nacional Autónoma de México - Instituto de Investigaciones Sociales. México.

Fuller, Norma 2009. Turismo y cultura: Entre el entusiasmo y el recelo. Fondo Editorial de la Pontificia Universidad Católica del Perú, primera edición. Perú.

Giddens, Anthony 1995. La constitución de la sociedad: Bases para la Teoría de la Estructuración. Amorrortu editores, Argentina.

Goetz M. 1988. Etnografía y diseño cualitativo en investigación educativa; disponible en http://etac. clientes.tralcom.com/tc-etac/cursos/Caulitativa_contenido/html/lecturas/28\%20DISTINCION\%20 ENTRE\%20LA\%20ETNOGRAFIA\%20Y\%20OTROS\%20MODELOS\%20DE\%20INVESTIGACION. pdf; consultado el 18 de marzo del 2020.

Mignolo, Walter D. 2000. La colonialidad a lo largo y a lo ancho: El hemisferio occidental en el horizonte colonial de la modernidad. Editorial CLACSO, Consejo Latinoamericano de Ciencias Sociales. Buenos Aires, Argentina. Consultado en http://biblioteca.clacso.edu.ar/clacso/sur-sur/20100708044529/5_mignolo.pdf el 10 de diciembre del 2019.

Montes de Oca Barrera, Laura Beatriz. 2015. Entre activistas, funcionarios e industriales: Aplicación de la etnografía -enfocada y política- en escenarios de gobernanza. Nueva antropología, 28(83), 25-46. Consultado en http://www.scielo.org.mx/scielo.php?script=sci_arttext\&pid=S0185-06362015000200003\&ln $\mathrm{g}=\mathrm{es} \&$ tlng=es el 10 de diciembre del 2019.

SECTUR 2018. Información turística por entidad federativa, Ciudad de México, consultado en http:// www.datatur.sectur.gob.mx/ITxEF/ITxEF_DF.aspx el 23 de septiembre del 2018.

Thompson, John B. 1988. La teoría de la estructuración; una valorización de las contribuciones de A. Giddens. Revista Sociológica, Vol. 3 (7-8), Universidad Autónoma Metropolitana, México.

Torres Ortiz, Susana 2010. La consigna de Cuauhtémoc en el siglo XXI. En Camarena Ocampo, Mario (coord.); La Construcción de la Memoria Colectiva. Editorial Escuela Nacional de Antropología e Historia - posgrado. ENAH, México.

\section{Notes}

1 El Anáhuac es la parte norte y centro del hoy conocido como continente americano, el cual tenía centro en Tenochtitlán; mientras que el Tawantinsuyo tenía su centro en Cuzco (Mignolo, 2000: 60).

2 Masaje que tiene como objetivo liberar el estrés, alinear la columna vertebral y corregir la postura del cuerpo del cliente. 3 Referencia temporal sobre el gobierno de Cuauhtémoc para señalar la época previa a la Colonia en México (Torres, 2010: 61).

4 Término dado por los mexicas al territorio que según Mignolo (2000: 60) es la parte norte y centro del hoy conocido como continente americano, el cual tenía centro en Tenochtitlán. 